\title{
INCOME SHOCKS AND SUICIDES: CAUSAL EVIDENCE FROM INDONESIA
}

\author{
Cornelius Christian, Lukas Hensel, and Christopher Roth*
}

Abstract-We examine how income shocks affect the suicide rate in Indonesia. We use a difference-in-differences approach, exploiting the cash transfer's nationwide rollout, and corroborate the findings using a randomized experiment. Our estimates show that the cash transfers reduce the yearly suicide rate by 0.36 per 100,000 people, corresponding to an $18 \%$ decrease. Moreover, a different type of income shock, variability in agricultural productivity, also affects the suicide rate. The cash transfer program reduces the causal impact of the agricultural productivity shocks, suggesting an important role for policy interventions. Finally, we provide evidence for depression as a psychological mechanism.

\section{Introduction}

$\mathrm{S}$ UICIDE is a pressing public health concern, causing 800,000 deaths per year globally (WHO, 2014). Suicidal behavior is one of the leading causes of death for people with severe mental illness (Hawton et al., 2013). While the effects of economic conditions on mental health and depression are well established (Baird, McIntosh, \& Özler, 2011; Haushofer \& Shapiro, 2016), little is known about the causal effect of economic well-being on suicidal behavior. More specifically, no causal evidence exists that examines whether positive income shocks, such as poverty alleviation programs, can decrease suicides.

It is difficult to credibly quantify the impact of improved economic well-being and, in particular, poverty alleviation programs on suicide rates. First, it is challenging to find suicide data at sufficiently low levels of geographic disaggregation to ensure statistical power. Second, the timing and geographic placement of large government programs are usually endogenous, and even if small-scale programs demonstrate causality, external validity concerns predominate (Deaton, 2010; Allcott, 2015).

Our data and empirical setting address these difficulties. We focus on Indonesia, the world's fourth most populous country. We leverage unique Indonesian village-level census data from 2000 to 2014 and use several identification strategies to examine the causal effect of income shocks: The

Received for publication October 29, 2016. Revision accepted for publication August 15, 2018. Editor: Rohini Pande.

${ }^{*}$ Christian: Brock University; Hensel: University of Oxford; Roth: Institute on Behavior and Inequality.

We thank the coeditor, Rohini Pande, and four anonymous referees for very useful suggestions. We thank Damian Clarke, Jon de Quidt, Esther Duflo, Jan Emanuelle De Neve, James Fenske, Thomas Graeber, Alexis Grigorieff, Ingar Haaland, Johannes Haushofer, Johannes Hermle, Matt Lowe, Climent Quintana-Domeque, Simon Quinn, Timo Reinelt, Marc Witte, and Johannes Wohlfart for comments and help. We thank Jessica Topping for excellent research assistance. We also thank various conference and seminar participants for comments on the paper. We are grateful to Sudarno Sumarto, Jan Priebe, Matthew Gudgeon, the National Team for the Acceleration of Poverty Reduction (TNP2K), and the World Bank for sharing several sources of data. Any errors are our own.

A supplemental appendix is available online at http://www.mitpress journals.org/doi/suppl/10.1162/rest_a_00777. first is a conditional cash transfer program, Program Keluarga Harapan (PKH), which provides households with yearly cash transfers worth about $10 \%$ of their pretreatment annual consumption over six years. Using a difference-in-differences specification, we estimate the effect of the program's nationwide rollout. The program targeted subdistricts with high levels of poverty rates, sufficient supply-side health, and educational institutions and was launched in 2007 when it covered $13 \%$ of Indonesian subdistricts in seven provinces. The program was widely expanded, reaching $57 \%$ of subdistricts across all 33 provinces in 2013. We use two stages of the rollout as identifying variation: the first stage of subdistricts that received the treatment from 2007 to 2011 and the second stage of subdistricts that received the treatment in 2012 and 2013. We also analyze a randomized controlled trial of the same program. Second, we exploit plausibly exogenous agricultural productivity shocks, using rainfall variation, and examine whether the effects of the cash transfer vary systematically with these agricultural productivity shocks.

We establish several novel facts regarding the relationship between economic well-being and suicides. Our first finding is that both the cash transfer's rollout and the randomized cash transfer cause a large reduction of suicides. Our main specification suggests that an average per capita transfer of US $\$ 22.45$ targeted at the poorest $10 \%$ of households causes a decrease in the suicide rate by approximately 0.36 suicides per 100,000 population per year. This corresponds to a reduction of the suicide rate by approximately $18 \%$ relative to the mean suicide rate (in 2011 and 2014) of two suicides per 100,000 in control subdistricts. Second, we show that agricultural productivity shocks, proxied by rainfall, significantly affect the incidence of suicide. A 1 standard deviation increase in rainfall increases yearly per capita consumption by $\$ 21.60$ and decreases the number of suicides per 100,000 inhabitants by approximately 0.08 , corresponding to a reduction of $6 \%$ relative to the average suicide rate in Indonesia between 2000 and 2014. For the subsamples affected by the income shocks, our calculations suggest that per-dollar effects on suicides identified using rainfall are significantly smaller than those from cash transfers. Third, we establish that cash transfers lower suicides most strongly in subdistricts experiencing negative agricultural productivity shocks. This is consistent with social welfare programs mitigating the adverse effects of negative economic shocks.

Finally, we provide evidence that income shocks may ignite suicidal behavior by affecting people's mental health. The medical literature suggests that stress (Mann et al., 1999) and mental illness, such as depression, are major causes of suicides (Boldrini \& Mann, 2015). We use panel data from the Indonesian Family Life Survey to show that agricultural 
productivity shocks causally affect farmers' mental health. A 1 standard deviation increase in subdistrict-level rainfall increases consumption by approximately $7 \%$ and reduces depression by 0.12 of a standard deviation. Moreover, the relationship between rainfall and depression is absent for nonfarmers, indicating that the effects of rainfall operate through an economic channel.

We contribute to the literature on how economic and social circumstances affect suicides (Becker \& Woessmann, 2018; Campaniello, Diasakos, \& Mastrobuoni, 2017; Cutler, Glaeser, \& Norberg, 2001; Daly, Wilson, \& Johnson, 2013; Ludwig, Marcotte, \& Norberg, 2009; Stevenson \& Wolfers, 2006). Concurrent work by Carleton (2017) shows that across Indian states, for temperatures above $20^{\circ} \mathrm{C}$, a $1^{\circ} \mathrm{C}$ rise causes roughly seventy suicides per day, particularly during the agricultural growing season. ${ }^{1}$ Our evidence supports the view that the positive effects of the cash transfer program on recipients' mental health (Haushofer \& Shapiro, 2016) outweigh negative spillovers of such programs (Baird et al., 2013).

Our paper also contributes to the literature on poverty, income shocks, and mental health, the last of which is usually measured through self-reported scales (Adhvaryu, Fenske, \& Nyshadham, 2019; Baicker et al., 2013; Cesarini et al., 2015; Das et al., 2007; Devoto et al., 2012; Friedman \& Thomas, 2009; Gardner \& Oswald, 2007; Kling, Liebman, \& Katz, 2007; Kuhn et al., 2011; Persson \& Rossin-Slater, 2018). In particular, previous papers examine the effects of randomized cash transfers on mental health through survey questions (Baird, De Hoop, \& Özler, 2013; Paxson \& Schady, 2007). An exception is Haushofer and Shapiro (2016), who show that large, unconditional cash transfers can reduce cortisol levels, consistent with self-reported reductions in stress.

Our study advances the literature on poverty and mental health in three ways. First, we provide the first causal evidence on whether positive income shocks and, in particular, government poverty alleviation programs, reduce suicides. Second, unlike previous evidence on income shocks and mental health which mostly relies on small-scale experiments, we use both a large-scale nationwide rollout of a conditional cash transfer program and a randomized evaluation of the same program. Finally, we provide the first evidence on the interaction between social welfare programs and agricultural productivity shocks on mental health, underlining the potential of government programs to alleviate negative consequences of adverse economic shocks.

We proceed as follows. In section II, we outline a conceptual framework and describe the data and the cash transfer program. In section III, we present our identification strategies and describe our results using both the cash transfer and agricultural productivity shocks. In section IV, we examine mechanisms underlying our estimated treatment effects by employing microdata on depression. In section $\mathrm{V}$, we discuss effect sizes and conclude in section VI.

\footnotetext{
${ }^{1}$ There is also correlational evidence highlighting that recessions increase suicides (Chang et al., 2013; Reeves et al., 2012).
}

\section{Conceptual Framework, Context, and Data}

In this section we describe the conceptual framework, the main features of the conditional cash transfer program, the suicide data, and the construction of the subdistrict panel. Finally, we report some basic descriptive statistics about Indonesian suicide rates.

\section{A. Conceptual Framework}

What are the theoretical links between economic wellbeing and suicides? Previous psychiatric disorders are the most important factor in explaining death by suicide; $90 \%$ of those who committed suicide had such a disorder (Cavanagh et al., 2003). Hawton et al. (2013) claim that specific mental health problems, such as depression, are mainly responsible for the decision to commit suicide. Poverty and negative economic shocks are also associated with mental health disorders and depression in particular (Haushofer \& Fehr, 2014; McInerney, Mellor, \& Nicholas, 2013; Schilbach, Schofield, \& Mullainathan, 2016). Negative life experiences, such as loss of income and job loss, have also been identified as risk factors for suicide. ${ }^{2}$

Stress is a likely mechanism at play, as suicide risk is correlated with abnormal cortisol concentrations and a maladaptive cortisol response to stress (O'Connor \& Nock, 2014). This is in line with psychological models of suicide, which emphasize that preexisting medical conditions coupled with stress lead to suicidal behavior (Mann et al., 1999). ${ }^{3}$

The main object of interest in this paper is to understand how economic shocks affect the suicide rate. Positive economic shocks could affect the suicide rate directly by mitigating the consequences of negative life experiences or through improvements in mental health. In section IV, we provide suggestive evidence in support of mental health as a channel by analyzing the relationship between economic shocks and depression.

Functional form. Our data and setting allow us to provide evidence on the functional form of the relationship between the suicide rate and income. Models of reference-dependent preferences predict declining effects of permanent income shocks over time as individuals' reference points adapt to the income level. ${ }^{4}$ Indeed, previous evidence suggests that the effects of permanent improvements in economic circumstances

\footnotetext{
${ }^{2}$ In addition, there is a literature emphasizing that suicides can be contagious - that the social environment plays an important role (Hedström, Liu, \& Nordvik, 2008). There is also work that examines how genes (Roy, 1992), social isolation (Appleby et al., 1999), and personality traits (Blüml et al., 2013) affect people's tendency to commit suicide.

${ }^{3}$ Joiner (2005) puts forward an interpersonal theory of suicide, which posits that the coexistence of high feelings of burdensomeness, low levels of belongingness, and the belief that these conditions are hopeless to change, lead to the development of suicidal desires. Finally, social isolation and lack of social support consistently predict suicide risk (Appleby et al., 1999).

${ }^{4}$ Models in which the reference point fully adapts after one period predict that there is a fall in suicides only in the first year of a permanent income shock and no effects thereafter.
} 
on self-reported mental well-being decline over time as individuals adapt to their new economic situation (Frederick \& Loewenstein, 1999; Galiani, Gertler, \& Undurraga, 2018). We test the predictions of models of reference dependence by analyzing the dynamic treatment effects over the program duration of six years.

If the marginal impact of income on the suicide rate decreases in income, then we expect a convex relationship between the suicide rate and income. In this case, the impact of a positive income shock should be larger if the recipients of the shock are poorer to begin with. If the relationship is linear, there should be no heterogeneity by initial poverty levels. We test the implications of different functional forms by analyzing treatment heterogeneity of the cash transfer program by the extent of initial poverty, as proxied by agricultural productivity shocks. We also use microdata to test whether the effects of agricultural productivity shocks on depression depend on initial poverty as proxied by pretreatment percapita household consumption.

Types of income shocks. Different types of income shocks may have different quantitative impacts on the suicide rate. The effect of an income shock likely depends on its effect on expected lifetime income and the uncertainty about lifetime income, that is, its current consumption value. Therefore, predictable and regular cash transfers should have larger per dollar impacts on the suicide rate than unpredictable agricultural income shocks, a prediction we test in this paper.

\section{B. The Conditional Cash Transfer Program}

We use the Program Keluarga Harapan (PKH) conditional cash transfer program to analyze the impact on suicide rates (Banerjee et al., 2017; Cahyadi et al., 2018; World Bank, 2011). A pilot version of the PKH was introduced in 2007 for 600,000 households, and the program was then expanded to cover 5.2 million households in 2014 with a target of 10 million recipients in 2018 (World Bank, 2017). The introduction of the PKH program was part of a wider effort to reform the Indonesian social security system. In 2005 the Indonesian government removed universal fuel subsidies. To alleviate the immediate inflationary shock for poor and near-poor households, the government introduced an unconditional cash transfer program covering 19 million households from 2005 to 2006. Furthermore, existing large-scale social assistance programs, such as rice subsidies for poor households (Beras untuk Rakyat Miskin, or Raskin) and subsidized health insurance for the poor (Asuransi Kesehatan Miskin, Askeskin), were expanded. The PKH program was introduced in 2007 after the unconditional cash transfer ended to provide more targeted assistance to the poorest households (World Bank, 2012). ${ }^{5}$

\footnotetext{
${ }^{5} \mathrm{PKH}$ 's coverage is significantly below of that of the other social benefit programs, but due to its targeted nature, the World Bank considers it one
}

PKH was designed to improve poor households' health and education through a cash transfer, conditional on their participation in health and education services (World Bank, 2011). The intervention's size was substantial: households annually received between $\$ 39$ and $\$ 220$ (all amounts in U.S. dollars). The average received amount constituted about $10 \%$ of pre-PKH yearly household expenditure $(\$ 80.82$ at 2005 prices) between 2007 and 2014 (World Bank, 2011, 2017). Households were part of the PKH program for up to six years.

The total cost of the PKH program from 2007 to 2014 was around $\$ 716$ million at 2005 prices. In total, there were 7.6 million household-years of cash transfer such that the average expenditure per household-year was $\$ 94.00$ (World Bank, 2017). According to the 2011 village census, the average household size in Indonesia in 2011 was 3.6 individuals, which implies an expenditure of $\$ 26.11$ per treated individual and year. Subtracting administrative overhead, households received $\$ 22.45$ per capita on average.

Geographic rollout of program. In section IIIA, we exploit two stages of the rollout of the PKH program as identifying variation for the difference-in-differences estimation: the first stage of subdistricts that received the treatment from 2007 to 2011 and the second stage of subdistricts that received the treatment in 2012 and 2013. The program was first implemented as a pilot program in 2007 in seven provinces: West Java, East Java, North Sulawesi, Gorontalo, East Nusa Tenggara (NTT), West Sumatra, and DKI Jakarta. These provinces are quite diverse in terms of their poverty levels and other economic and geographic characteristics. Because the program's focus is on poverty alleviation, upper-income quintile districts were initially excluded from PKH eligibility, based on an index considering poverty rates, malnutrition, and schooling records. ${ }^{6}$ Most of the 2007 rollout of the program was randomized among selected eligible districts.

From 2008 to 2010, the program maintained its pilot status but was expanded in the following provinces: Nanggroe Aceh Darussalam, North Sumatra, Banten, South Kalimanten, West Nusa Tenggara, and the Yogyakarta Special Region. Since 2010 the Secretariat of the National Team for the Acceleration of Poverty Reduction (TNP2K), at the Office of the Vice-President, has been promoting the nationwide expansion of PKH leading to all Indonesian provinces being covered by 2012. Of the subdistricts included in our analysis, the PKH program covered about $13 \%$ of all Indonesian subdistricts when it started in 2007. By 2013, 57\% of all Indonesian subdistricts in our sample were in receipt of the program.

At the macrolevel, targets for overall recipient numbers and total expenditure were set at the national level, which determined the overall speed of the rollout. At the microlevel,

of the most effective Indonesian social assistance programs (World Bank, 2017).

${ }^{6}$ Districts receiving the rural community-driven development project were eligible for the community cash transfer program (PNPM Generasi) and therefore were ineligible for the $\mathrm{PKH}$ program during the pilot operation. 
target subdistricts were determined in cooperation with provincial and district governments that made recommendations. The final decisions took into account three main factors: subdistrict poverty levels, existence of the necessary supplyside institutions (e.g. educational institutions and health centers), and the willingness of local partners to cooperate.

Randomized experiment. In section IIIB, we use a subsample of subdistricts in which the treatment status was randomly assigned and formed the basis for the World Bank's evaluation of the program (World Bank, 2011). A total of 736 subdistricts were included in the sample, with 438 subdistricts randomized to the treatment group (Cahyadi et al., 2018). Of these, we observe treatment assignment for the 360 subdistricts that were randomly chosen for data collection by the World Bank (180 treatment, 180 control). Political pressures and a consequent unexpected program expansion in East Java resulted in deviations of the realized allocation from the intended one. ${ }^{7}$ To deal with this contamination, we use the original treatment assignment to measure the conditional cash transfer program's impact on suicide.

Beneficiary selection. At the subdistrict level, the cash transfer program was offered to a list of eligible households that satisfied both demographic and economic requirements. A 2005 census from a national unconditional cash transfer program was initially used to construct the list of eligible households per village. Approximately $30 \%$ to $40 \%$ of beneficiaries from the unconditional cash transfer program were not included in the list of eligible households. ${ }^{8}$ Based on this list of households, demographic data were used to identify eligible households that fulfilled one of the following program criteria: (a) households with pregnant and/or lactating women, (b) households with children aged 0 to 15 years, and (c) households with children aged 16 to 18 years who had not yet completed nine years of basic education. However, only the subset of eligible households with the lowest predicted consumption were included in the program. In the end, approximately $10 \%$ of households received the program. The classification was based on proxy-means tests of all households on the list of eligibles to identify program beneficiaries. The proxy-means tests consisted of 29 variables, including housing characteristics, education levels, sources of fuel, employment information, and access to health and education services.

\footnotetext{
${ }^{7}$ In particular, 37 of the 360 subdistricts that were supposed to be part of the control group received PKH funds before 2011. Moreover, for a very few subdistricts, the program started in 2008 or 2009 rather than in 2007. Bias might result from this contamination, since it is possible that unobserved factors within the contaminated subdistricts also affected household responses. The contamination increased further, leading to $30 \%$ of control subdistricts receiving the program by 2014 .

${ }^{8}$ Statistics Indonesia also conducted additional interviews in targeted subdistricts to identify newly poor households in an attempt to minimize exclusion errors.
}

\section{Data}

We use the censuses of all Indonesian villages (PODES) from 2000, 2003, 2005, 2011, and 2014 to examine the PKH program's effect on suicide rates. The PODES data cover all 80,000 villages in Indonesia. In the village census, village heads report village characteristics, such as population size, the presence of health and educational institutions, and the percentage of farmers.

Outcome definitions. The census contains data on suicides at the village level. In 2000, 2003, and 2005, the village heads were asked whether any suicide occurred in their village in the previous year. In 2011, they were asked about the number of suicides committed in the past year. Finally, in 2014, the PODES survey asked for the number of suicides and suicide attempts in the village during the past year. Village-level population data are available from 2000 to 2011 but not for 2014 . To obtain population data for 2014 , we extrapolate population size using a linear trend from the years 2005 and 2011 to 2014 at the subdistrict level.

We use the PODES census data to construct the main outcome measure of interest: the number of suicides per 100,000 inhabitants at the subdistrict level. For the years 2000, 2003, and 2005 (all prior to the cash transfer program), we use the number of villages with at least one suicide per 100,000 inhabitants as a proxy for the actual suicide rate. For the PODES 2011 data, we directly use the number of suicides per 100,000 inhabitants at the subdistrict level. And we define the suicide rate in 2014 as the number of suicides and suicide attempts per 100,000 inhabitants.

We also construct a measure of the suicide rate for which the definition does not vary across years (except for 2014 when the question included suicide attempts). Specifically, we extrapolate the expected suicide rate from the subdistrict mean of village-level occurrences of at least one suicide. This requires two assumptions: (a) we assume that suicides are Poisson distributed and (b) suicides in all villages of the same subdistrict are independent and have the same Poisson parameter $\lambda$. Under these assumptions, we can use the mean incidence of at least one suicide $(\bar{s})$ to calculate the expected number of suicides $E_{v}(s)$ in a given village as $E_{v}(s)=-\ln (1-\bar{s}) .{ }^{9}$ To calculate the expected number of suicides at the subdistrict level, we multiply $E_{v}(s)$ by the number of villages in a subdistrict. We validate this measure with data on the actual number of suicides in the years 2011 and 2014 and find a correlation of $\rho=0.95$. Moreover, in section IIID, we show that our results are robust to using different outcome measures.

\footnotetext{
${ }^{9}$ This is derived from the cumulative distribution function of the Poisson distribution: $C D F(k)=e^{-\lambda} \sum_{i=0}^{\lfloor k\rfloor} \frac{\lambda^{i}}{i !}$. We observe the fraction of villages with 0 reported suicides, which gives a subdistrict-specific estimate of $C D F(0)$. Expressed as a fraction of villages with at least one suicide, we get $C D F(0)=1-\bar{s}$. Using the functional form of the Poisson distribution, we obtain $E_{v}(s)=\lambda=-\ln (1-\bar{s})$. There is one subdistrict in 2014 where all villages have at least one suicide or suicide attempt. For this observation, we use the average subdistrict $\lambda$ over the preceding four census waves.
} 
According to the WHO Health Data repository, the agestandardized suicide rate in Indonesia stood at around 3 per 100,000 in 2015 . This seems relatively well aligned with our data, where we find mean raw suicide rates of approximately 2 per 100,000 at the subdistrict level in 2011 and 2014. ${ }^{10}$

Indonesia has low suicide rates from an international perspective. In a WHO world-wide ranking of all nations by suicide rates, Indonesia ranked 173 out of 183 nations. This low baseline suicide rate could imply stronger social norms against suicides in Indonesia. These norms might not only affect the level of the suicide rate, but also the elasticity of suicides with respect to economic shocks. However, it is theoretically unclear how these norms would affect the relationship between the suicide rate and economic circumstances. On the one hand, decisions to commit suicide might be more marginal than in other countries, that is, a small improvement in economic circumstances could prevent more suicides. On the other hand, it is possible that because of the strong stigma, noneconomic factors play a more important role for suicides in Indonesia.

Subdistrict panel construction. Since our key identifying variation is at the subdistrict level, we aggregate our village panel at the subdistrict level and collapse our observations at the subdistrict boundaries from 2000 . We use these subdistrict boundaries as 2000 is the first year for which suicide data are available. ${ }^{11}$ For practical reasons we construct our panel at the subdistrict level as the number of administrative units in Indonesia substantially increased over time. ${ }^{12}$ In the experimental sample, there are 314 subdistricts according to 2000 boundary definitions. In our analysis, we make use of only 310 subdistricts for which we can construct a crosswalk between 2000 and 2014. For the rollout of the program and the analysis of agricultural productivity shocks (presented in section IIID), we employ the universe of Indonesian subdistricts for which we could construct a consistent panel between 2000 and 2014. We were able to construct such a panel for 3,138 out of all 3,928 subdistricts according to 2000 boundary definitions. The panel's construction was based on a subdistrict-level crosswalk for the period 2000 to 2014. Owing to the subdistrict splits, there are 1,485 cases

\footnotetext{
${ }^{10}$ The slight discrepancy between those numbers can be explained by the fact that the WHO estimates are model based and only partially take into account microdata on suicides in Indonesia.

${ }^{11}$ We use 2000 borders to provide a consistent interpretation of coefficients for all our subdistrict-level specifications. Furthermore, using subdistrict border definitions from after 2000 would complicate both the presentation of pretrends and the analysis of interactions between agricultural productivity shocks and cash transfers (presented in sections IIIA and IIIF). We show that our results are robust to using the 2006 subdistrict borders (tables A.8 and A.14 in the online appendix).

${ }^{12}$ Decentralization reforms beginning from 1998 significantly increased the proliferation of administrative units. For example, the number of districts increased from 302 in 1999 to more than 500 in 2014 (Bazzi \& Gudgeon, 2018). The number of subdistricts increased from about 3,000 in the late 1990 s to approximately 7,000 in 2014. Constructing a crosswalk at the village level is particularly challenging and would necessarily result in a large number of incorrect matches over time. This would substantially increase the measurement error of outcomes.
}

in which a subdistrict split from 2000 to 2014. If only part of the 2000 subdistrict received the cash transfer in a given year, we define the treatment indicator as the fraction of new subdistricts receiving the PKH program. When we drop the observations with partially treated origin subdistricts, our estimated treatment effects barely change (see tables A.6 and A.12).

Descriptives and correlates of suicide rates. Table 1 displays descriptive statistics at the subdistrict level from the PODES 2005 data, before the cash transfer was implemented. On average, a subdistrict consists of 17.2 villages and has a population of approximately 56,000. Most subdistricts are relatively rural, with on average $74 \%$ of villages classified as rural and $56 \%$ of the population working as farmers. Thus, agricultural productivity shocks are likely to affect large parts of the population. The randomized controlled trial (RCT) sample is more rural than the average, but otherwise is similar to non-RCT subdistricts.

We exploit baseline data from the 2005 census to characterize the correlates of suicides. We find a strong economic gradient in suicide rates. Subdistricts in districts with a $10 \%$ larger share of the households below the poverty line have, on average, a 0.142 higher suicide rate per 100,000 people (see column 1 of table A.1 in the online appendix). The same pattern is apparent when we consider per capita expenditures at the district level. The share of farmers at the subdistrict level is strongly positively correlated with suicide rates. The share of farmers at the subdistrict level remains significantly correlated with suicide rates after controlling for local crime rates, health, education, and social institutions. ${ }^{13}$ Table A.1 also reveals that crime per capita is weakly positively related to suicide incidence, but that social organizations per capita and educational institutions per capita are not correlated with suicide rates. ${ }^{14}$

Finally, we observe an increase in the occurrence of any suicide in subdistricts over time. The incidence of at least one suicide at the subdistrict level increased from $21 \%$ in 2000 to $45 \%$ in 2005 and $52 \%$ in 2011 and $2014 .^{15}$

\footnotetext{
${ }^{13}$ Since the share of farmer variable is available at the subdistrict level, this may explain why it remains statistically significant, while per capita expenditure and fraction poor, which are measured at the district level, become statistically insignificant.

${ }^{14} \mathrm{We}$ find that health institutions per capita are positively correlated with suicide rates, consistent with the government's targeting health care provisions to needier subdistricts.

${ }^{15}$ The increase in reported suicides between 2000 and 2005 could be the result of shifting norms around suicides, potentially affecting the willingness of village chiefs to report suicides. However, such a shift in norms is unlikely to affect the direction and magnitude of our treatment effects estimates. For our preferred specification, we rely on data from 2005 to 2014, directly avoiding the influence of potential underreporting in 2000 and 2003. Furthermore, even when we include the 2000 and 2003 census waves, the treatment effect point estimate hardly changes, suggesting a limited role of this underreporting. Finally, a shift of norms could affect the direction of the treatment effect only if it occurred differentially in subdistricts with and without the cash transfer program and in subdistricts with and without agricultural productivity shocks. Comparing other measures of suicides over time is complicated by changing survey questions and changes in the number of villages per subdistrict.
} 
TABle 1.-SumMary Statistics

\begin{tabular}{|c|c|c|c|c|c|c|}
\hline & Mean & SD & Median & Minimum & Maximum & Observations \\
\hline \multicolumn{7}{|l|}{ A. Population data } \\
\hline Suicide rate & 1.39 & 2.14 & 0.65 & 0.00 & 64.52 & 3138 \\
\hline Any suicide & 0.53 & 0.50 & 1.00 & 0.00 & 1.00 & 3138 \\
\hline Educational institution/100,000 population & 152.03 & 49.66 & 146.20 & 11.84 & 781.56 & 3138 \\
\hline Health institution/100,000 population & 181.98 & 59.06 & 174.19 & 17.88 & 788.13 & 3138 \\
\hline$\%$ village with paved road & 0.72 & 0.32 & 0.83 & 0.00 & 1.00 & 3138 \\
\hline$\%$ village with lighting & 0.78 & 0.32 & 1.00 & 0.00 & 1.00 & 3138 \\
\hline$\%$ rural villages & 0.74 & 0.40 & 1.00 & 0.00 & 1.00 & 3138 \\
\hline Number of villages & 17.22 & 12.75 & 14.00 & 2.00 & 137.00 & 3138 \\
\hline Population size & 56,021 & 40,427 & 47,484 & 2,371 & 415,394 & 3,138 \\
\hline Number of families & 14,090 & 9,851 & 12,182 & 540 & 90,682 & 3,138 \\
\hline Percentage farmers & 56.84 & 30.97 & 67.17 & 0.00 & 100.00 & 3,138 \\
\hline \multicolumn{7}{|l|}{ B. Early adopters (2007-2011) } \\
\hline Suicide rate & 1.31 & 1.86 & 0.55 & 0.00 & 14.31 & 713 \\
\hline Any suicide & 0.54 & 0.50 & 1.00 & 0.00 & 1.00 & 713 \\
\hline Educational institution/100,000 population & 142.78 & 49.19 & 139.42 & 58.82 & 475.15 & 713 \\
\hline Health institution/100,000 population & 173.71 & 53.78 & 170.60 & 17.88 & 480.05 & 713 \\
\hline$\%$ village with paved road & 0.77 & 0.30 & 0.92 & 0.00 & 1.00 & 713 \\
\hline$\%$ village with lighting & 0.86 & 0.27 & 1.00 & 0.00 & 1.00 & 713 \\
\hline$\%$ rural villages & 0.73 & 0.41 & 1.00 & 0.00 & 1.00 & 713 \\
\hline Number of villages & 14.03 & 7.36 & 13.00 & 3.00 & 77.00 & 713 \\
\hline Population size & 63,903 & 43,382 & 53,035 & 5,594 & 314,932 & 713 \\
\hline Number of families & 15,996 & 10,030 & 13,546 & 1,523 & 68,967 & 713 \\
\hline Percentage farmers & 51.89 & 31.32 & 62.09 & 0.00 & 98.06 & 713 \\
\hline \multicolumn{7}{|l|}{ C. Randomized controlled trial data } \\
\hline Suicide rate & 1.41 & 1.98 & 0.63 & 0.00 & 14.50 & 310 \\
\hline Any suicide & 0.52 & 0.50 & 1.00 & 0.00 & 1.00 & 310 \\
\hline Educational institution/100,000 population & 161.63 & 49.83 & 151.46 & 69.72 & 475.15 & 310 \\
\hline Health institution/100,000 population & 181.80 & 43.36 & 176.57 & 82.88 & 504.15 & 310 \\
\hline$\%$ village with paved road & 0.70 & 0.29 & 0.79 & 0.00 & 1.00 & 310 \\
\hline$\%$ village with lighting & 0.78 & 0.32 & 0.98 & 0.00 & 1.00 & 310 \\
\hline$\%$ rural villages & 0.90 & 0.27 & 1.00 & 0.00 & 1.00 & 310 \\
\hline Number of villages & 16.74 & 6.85 & 16.00 & 3.00 & 46.00 & 310 \\
\hline Population size & 81,363 & 48,614 & 66,604 & 10,116 & 260,321 & 310 \\
\hline Number of families & 15,558 & 9,121 & 13,361 & 2,345 & 68,967 & 310 \\
\hline Percentage farmers & 60.00 & 23.85 & 64.00 & 0.00 & 98.00 & 310 \\
\hline
\end{tabular}

\section{Main Results}

In this section, we first present evidence from the difference-in-differences approach using the nationwide rollout of the cash transfer program. We then show results of an RCT of the same program. Thereafter, we examine the dynamics of treatment effects, and assess the robustness of our findings. Finally, we study how agricultural productivity shocks affect suicide rates and examine how they interact with the rollout of the cash transfer program.

\section{A. Nationwide Program Rollout}

We provide evidence that the PKH conditional cash transfer program substantially decreased the suicide rate using a difference-in-differences approach exploiting the nationwide rollout of the program. For our main specification, we use suicide data from the census of villages from 2005, 2011, and 2014, but we also employ data from 2000 and 2003 to assess robustness and pretrends. Our dependent variable is the number of suicides per 100,000 individuals $\left(y_{s t}\right)$ in subdistrict $s$ and at time $t$.
To estimate treatment effects, we include subdistrict fixed effects $\left(\alpha_{s}\right)$, time fixed effects $\left(\phi_{t}\right)$, and a treatment indicator, Treat $_{s t}$, taking a value of 1 when a subdistrict started receiving the program. ${ }^{16}$ This means that we effectively exploit differences in the timing of the receipt of the cash transfer program at the subdistrict level to estimate treatment effects. In particular, we use two stages of the rollout as identifying variation to estimate treatment effects: the first stage of subdistricts that received the treatment from 2007 to 2011 and the second stage of subdistricts that received the treatment in 2012 and 2013. We use all subdistricts that had not received the cash transfer program in a given census wave as controls. Although the identifying variation is at the subdistrict level, we cluster standard errors at the district level, as the rollout of the program was correlated at the district level. We estimate all of our main specifications with OLS and employ

\footnotetext{
${ }^{16}$ For subdistricts that split up over time, the treatment variable indicates the fraction of subdistricts (based on the 2000 boundary definitions) that receive the treatment.
} 
TABLE 2.-MAIN RESULTS: RoLlout

\begin{tabular}{|c|c|c|c|c|c|c|}
\hline \multicolumn{7}{|c|}{ Dependent Variable: Suicide Rate } \\
\hline & (1) & (2) & (3) & (4) & (5) & (6) \\
\hline Treatment & $-0.358^{* * *}$ & $-0.358^{* * *}$ & $-0.381^{* * *}$ & $-0.366^{* * *}$ & $-0.267^{* *}$ & $-0.591^{* * *}$ \\
\hline & $(0.101)$ & $(0.086)$ & $(0.110)$ & $(0.101)$ & $(0.115)$ & $(0.164)$ \\
\hline Subdistrict FE & Yes & Yes & Yes & Yes & Yes & Yes \\
\hline Time FE & Yes & Yes & Yes & Yes & Yes & Yes \\
\hline Cluster subdistrict & No & Yes & No & No & No & No \\
\hline Exclude RCT data & No & No & Yes & No & No & No \\
\hline Pretreatment data & No & No & No & Yes & Yes & No \\
\hline Subdistrict trends & No & No & No & No & Yes & No \\
\hline Population weights & Yes & Yes & Yes & Yes & Yes & No \\
\hline Control mean $(11 \& 14)^{\mathrm{a}}$ & 2.016 & 2.016 & 2.033 & 2.016 & 2.016 & 2.721 \\
\hline Number & 9,414 & 9,414 & 8,484 & 15,690 & 15,690 & 9,414 \\
\hline Census waves & 2005-2014 & $2005-2014$ & $2005-2014$ & $2000-2014$ & $2000-2014$ & 2005-2014 \\
\hline
\end{tabular}

The table displays the difference-in-differences estimate of the effect of the conditional cash transfer program on the suicide rate. All specifications include year and subdistrict fixed effects. Estimates are weighted using the 2005 population size unless otherwise noted. Standard errors are clustered at the district level unless otherwise noted. Column 2 reports standard errors clustered at the subdistrict level. Column 3 excludes the RCT sample (which we employ in table 3). Column 4 includes all pretreatment periods. Column 5 further includes subdistrict time trends. Column 6 does not use 2005 population weights to estimate treatment effects. The definition of the suicide rate per 100,000 people changes slightly over time. In 2014, it is defined as the number of suicides and suicide attempts per 100,000. In 2011, it is defined as the number of suicides per 100,000 . From 2000 to 2005 , the suicide rate is defined as the number of villages in a given subdistrict with at least one suicide per $100,000 .{ }^{*} p<0.10,{ }^{* *} p<0.05$, and ${ }^{* * *} p<0.01$.

a $(11 \& 14)$ refers to years of treatment.

population weights from $2005 .{ }^{17}$ Our specification of interest is

$$
y_{s t}=\delta_{1} \text { Treat }_{s t}+\alpha_{s}+\phi_{t}+\varepsilon_{s t} \text {. }
$$

Our main coefficient of interest is $\delta_{1}$, which provides us with the treatment effect for the subdistricts that had started receiving the program at the time of the data collection. Column 1 of table 2 shows that receiving the cash transfer program of on average $\$ 22.45$ per year reduces the number of suicides per 100,000 inhabitants by 0.36 . This corresponds to a reduction by approximately $18 \%$ relative to the control mean in 2011 and 2014. Our estimates remain economically and statistically significant when (a) clustering errors at the subdistrict level (column 2) and (b) excluding the sample of subdistricts with randomized treatment assignment employed in section IIIB (column 3), including all pretreatment periods (column 4) and including subdistrict-specific time trends (column 5). Column 6 displays the treatment effects that give equal weight to the subdistricts regardless of their population size in 2005 . This reveals an estimate of -0.591 suicides per 100,000 people, suggesting that the suicide reductions are larger in subdistricts with smaller population sizes. ${ }^{18}$

A key assumption underlying the difference-in-differences approach is that treatment and control subdistricts are on parallel trends. Figure 1 provides evidence supportive of the common trend assumption. ${ }^{19}$ It displays pretrends relative to

\footnotetext{
${ }^{17}$ We use population weights since the welfare-relevant metric of interest is change in the overall Indonesian suicide rate, not the average subdistrict suicide rate. Furthermore, the suicide rate is measured with less error in larger subdistricts, which increases the precision of our estimates.

${ }^{18}$ Our results are also robust to using district fixed effects instead of subdistrict fixed effects, controlling for district trends, including controls in a specification without subdistrict fixed effects, and allowing for differential trends by baseline covariates (table A.9).

${ }^{19} \mathrm{We}$ also provide further results consistent with parallel trends. Figure A.1 displays the evolution of mean suicide rates over time. Table A.3 shows that pretrends are uncorrelated with timing of entry (column 1) and that the level of the suicide rate in the period before a subdistrict received the program does not drive the treatment effects (column 2).
}

the timing of the introduction of the conditional cash transfer program by treatment wave. Differences in the first period before the treatment are normalized to 0 . The displayed coefficients are the difference-in-differences treatment effect estimates using subdistricts that had not received the PKH program until 2013 as counterfactuals. Moreover, as shown, the effects remain both economically and statistically significant after controlling for subdistrict-specific trends. We find consistently large negative and significant effects across a series of specifications. While we have provided evidence in support of the parallel-trend assumption, there is no formal test of the validity of this identification assumption.

\section{B. Randomized Controlled Trial}

In this section, we use the subdistricts in which the treatment was randomly assigned to test whether the experimental treatment effect estimates are in line with the nonexperimental rollout analysis from the previous section.

Balance. As a first step, we test whether the treatment and control group are balanced in terms of observables. Let $T_{s}$ denote the PKH program's original allocation, where $T_{s}=1$ if the subdistrict was randomly assigned to receive the program and $T_{s}=0$ otherwise. We consider whether baseline balance holds for the original treatment assignment by comparing means and clustering standard errors at the subdistrict level. In table A.2, we provide evidence of baseline balance on a set of observables. We cannot reject the null hypothesis of global balance $(p=0.57)$.

Results. We estimate treatment effects using the randomized assignment of the cash transfer program, clustering standard errors at the subdistrict level, and weighting observations by population size in $2005 .^{20}$ Despite the randomization of

\footnotetext{
${ }^{20} \mathrm{We}$ do not use the 2014 census in this section. While contamination of the randomization was quite low in 2011 (with 10\% of subdistricts having
} 
Figure 1.-Event-Study: Rollout of Conditional Cash Transfer Program

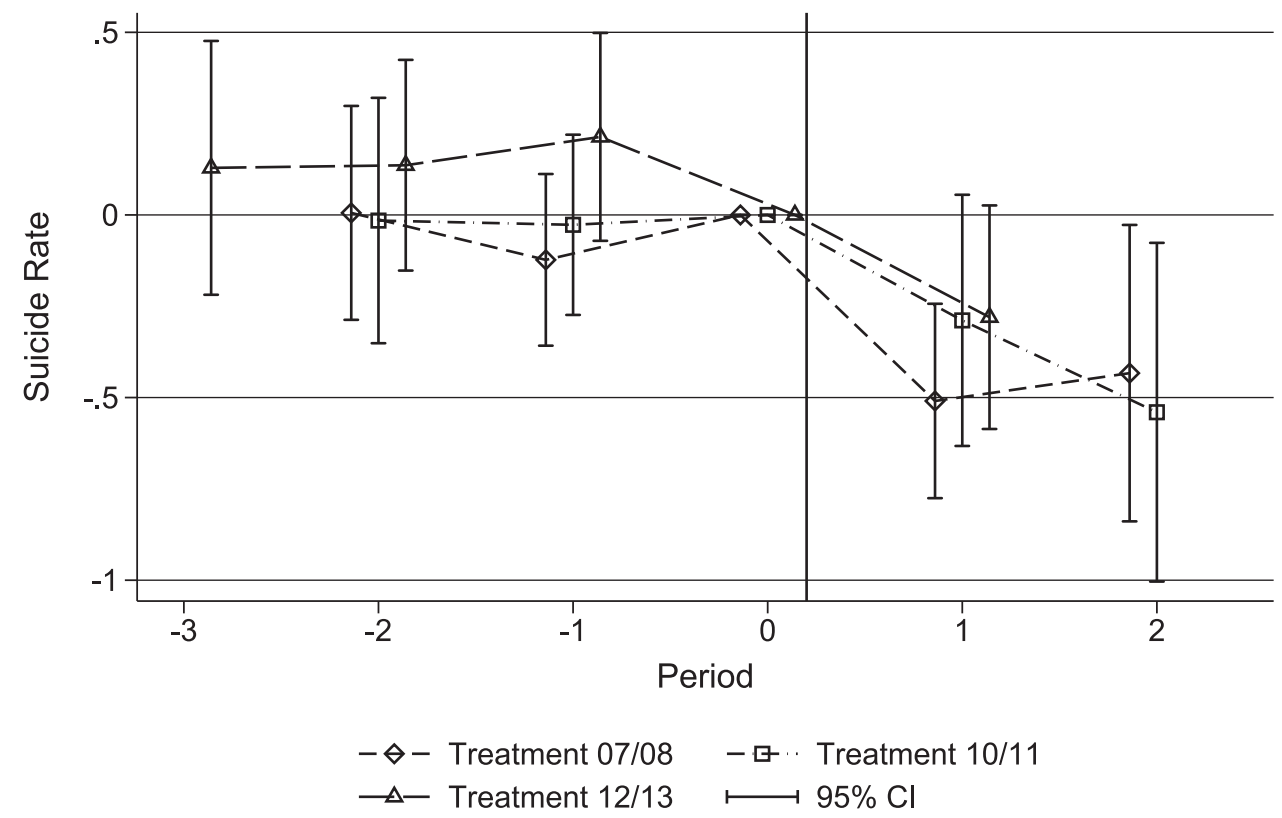

The figure displays treatment effects relative to the timing of the introduction of the conditional cash transfer program by treatment wave. The differences in the first period before the treatment are normalized to 0 . The displayed coefficients are the difference-in-differences treatment effect estimates relative to subdistricts that had not received the treatment until 2013. All standard errors are clustered at the district level. The vertical red line indicates the program start. The definition of the suicide rate per 100,000 people changes slightly over time. In 2014, it is defined as the number of suicides and suicide attempts per 100,000. In 2011, it is defined as the number of suicides per 100,000. From 2000 to 2005, the suicide rate is defined as the number of villages in a given subdistrict with at least one suicide per 100,000. The vertical line indicates the program start.

TABLE 3.-MAIN RESUlTS: RANDOMIZED EXPERIMENT

\begin{tabular}{|c|c|c|c|c|c|c|c|}
\hline \multicolumn{8}{|c|}{ Dependent Variable: Suicide Rate } \\
\hline & (1) & (2) & (3) & (4) & (5) & (6) & (7) \\
\hline Treatment & $\begin{array}{r}-0.337 \\
(0.266)\end{array}$ & $\begin{array}{r}-0.258 \\
(0.275)\end{array}$ & $\begin{array}{c}-0.665^{* *} \\
(0.318)\end{array}$ & $\begin{array}{c}-0.665^{* *} \\
(0.266)\end{array}$ & $\begin{array}{r}-0.466 \\
(0.334)\end{array}$ & $\begin{array}{r}-1.064^{*} \\
(0.593)\end{array}$ & $\begin{array}{r}-0.474 \\
(0.325)\end{array}$ \\
\hline Subdistrict FE & No & No & Yes & Yes & Yes & Yes & No \\
\hline Time FE & No & No & Yes & Yes & Yes & Yes & No \\
\hline Cluster district & No & No & No & Yes & No & No & No \\
\hline Pretreatment data & No & No & No & No & Yes & Yes & No \\
\hline Subdistrict trends & No & No & No & No & No & Yes & No \\
\hline Baseline suicide & Yes & No & No & No & No & No & Yes \\
\hline Population weights & Yes & Yes & Yes & Yes & Yes & Yes & No \\
\hline Control mean (2011) & 1.774 & 1.774 & 1.774 & 1.774 & 1.774 & 1.774 & 2.058 \\
\hline Number & 310 & 310 & 620 & 620 & 1,240 & 1,240 & 310 \\
\hline Census waves & 2011 & 2011 & 2005-2011 & 2005-2011 & 2000-2011 & $2000-2011$ & 2011 \\
\hline
\end{tabular}

The table displays the results of the RCT experiment. The suicide rate is defined as explained in table 2. Column 1 reports an ANCOVA specification using the 2011 suicide rates as the outcomes and controlling for the 2005 suicide rate. Column 2 displays the treatment effect estimate of a postcomparison of treated and control subdistricts. Columns 3 to 6 report difference-in-differences estimates of the treatment effect and control for both subdistrict and time fixed effects. Standard errors are clustered at the subdistrict level unless otherwise noted. In column 3, we report the baseline difference-in-differences specification using data from 2005 and 2011. Column 4 reports standard errors clustered at the district level. Column 5 includes data from the 2003 and 2000 census waves. Column 6 further includes subdistrict-specific time trends on top of subdistrict and time fixed effects. Column 7 shows the ANCOVA specification from column 1 without population weights. ${ }^{*} p<0.10,{ }^{* *} p<0.05$, and ${ }^{* * *} p<0.01$.

cash transfers at the subdistrict level, we find some evidence that treated subdistricts were on an upward trend compared to control subdistricts (figure A.4) and some gap in the suicide rate before the program was launched (table A.2). As a result of the common trend violation and the slight baseline imbalance, difference-in-differences estimators might be upward biased and a more conservative way of evaluating treatment effects is to employ an ANCOVA and a postestimator.

The ANCOVA specification in column 1 of table 3 shows that subdistricts randomly assigned to receive the same con-

an actual treatment status differing from the randomly assigned one), the contamination of the program strongly increased over time. By 2014,30\% of control subdistricts received the program. Moreover, the cash transfer ended in 2012 and 2013 so that only a subset of subdistricts was still receiving ditional cash transfer program as in section IIIA have, on average, a 0.337 lower suicide rate (about 19\% of the control mean in 2011). Comparing mean suicide rates between treatment and control subdistricts in 2011 also yields an insignificant average decrease of 0.258 suicides per 100,000 (column 2). While the magnitudes of the effects are economically meaningful and of very similar size to the rollout estimates, they are statistically insignificant. We attribute this lack of significance to low statistical power. ${ }^{21}$

the program during the relevant period from PODES 2014. We discuss the long-run effects of the PKH program in section IIIC.

${ }^{21}$ Ex-post power calculations show that we had $80 \%$ power to detect a 0.770 effect size at the 5\% level with the ANCOVA specification. 
Figure 2.-Dynamics of Treatment EFFECTS

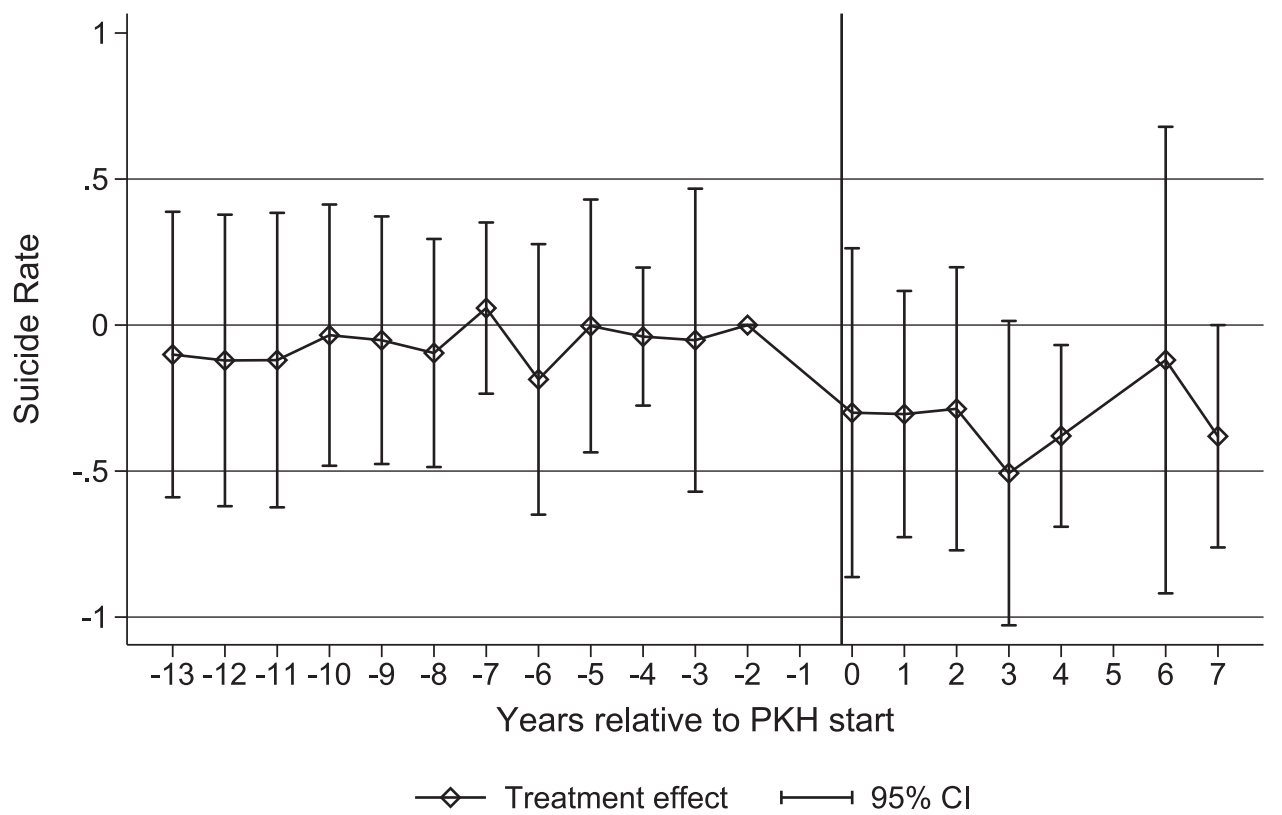

The figure displays the treatment effects on the suicide rate relative to the year of introduction of the conditional cash transfer program. The suicide rate is defined as in figure 1 . To estimate the coefficient for each year, we use different subsamples of subdistricts. Treated subdistricts in a given period $t$ are defined as having received the cash transfer program exactly $t$ before (or after) the census (e.g., to estimate the effect in year 1 , we use observations from the 2011 census subdistricts that received PKH in 2010 and observations of the 2014 census of subdistricts first receiving the PKH in 2013). For $t \geq 0$, control subdistricts are defined as subdistricts that had not received the treatment at the time of census. For $t<0$, control subdistricts are defined as not having received the treatment $t$ years after the census. Coefficients are obtained conditional on year and subdistrict fixed effects. Standard errors are clustered at the district level. The vertical line indicates the program start. Differences from two years before the treatment are normalized to 0.

We also estimate the effect of the RCT using differencein-differences specifications and find mostly significant negative treatment effects (columns 3 to 6 of table 3 ) confirming that the cash transfer program reduced suicides. However, given the pretrend violation and slight baseline imbalance, the effect sizes of the ANCOVA and postestimator are more credible. The results of the RCT are in line with the rollout results. The key difference between the two pieces of evidence is that the results from the rollout are much more precisely estimated as they are based on a ten-times-larger sample size than the estimates from the RCT.

\section{Dynamics of Treatment Effects}

In this section, we show that the cash transfer program had persistent treatment effects throughout the six-year duration of the program. To do so, we plot the evolution of the estimated treatment effect of the PKH program on suicide rates over time (see figure 2). To estimate the plotted coefficients, we exploit the fact that the census data collection occurred at different points in time relative to the beginning of the treatment for different subdistricts. This means that each point estimate is obtained by comparing a different sample of treatment and control subdistricts. ${ }^{22}$ Treated subdistricts in a given period $t$ are defined as having received the cash transfer pro-

\footnotetext{
${ }^{22}$ We do observe some treated subdistricts at two different points in time, which allows us to directly compare treatment effects over time (table A.16). The treatment effects for the subsample of treated subdistricts we observe twice are in line with the results from the overall sample.
}

gram exactly $t$ before (or after) the census. For $t \geq 0$, control subdistricts are defined as subdistricts that had not received the treatment at the time of the census. For $t<0$, control subdistricts are defined as not having received the treatment $t$ years after the census. This also leads to differences in sample size and precision in the estimation of treatment effects, as apparent by variation in the width of confidence intervals.

A clear temporal pattern emerges from figure 2. Similar to the rollout analysis, there are no detectable differences between treatment and control subdistricts in the years prior to receiving the cash transfer program. However, starting in the year subdistricts first receive the treatment cash transfer program, the suicide rate declines by about -0.3 in line with the aggregate analysis. The difference in the suicide rate persists throughout the six-year duration of the cash transfer program without any obvious changes in the effect size. ${ }^{23}$ The treatment effect also persists into year 7 after the treatment, potentially suggesting a persistence beyond the receipt of the program. However, the periods are defined in calendar years so that we cannot rule out that persistence is driven by subdistricts that started receiving the program in late 2007 still receiving the program at the time of the census data collection in early 2014.

These findings also imply that the duration of exposure to the treatment does not affect the estimated effects of the program. To more formally test this, we run a regression in which

\footnotetext{
${ }^{23}$ This finding is in line with evidence of constant and persistent effects of the PKH program on child health, education, and child labor (Cahyadi et al., 2018).
} 
we include a treatment indicator as well as a variable on the number of years of treatment that the subdistrict received. Duration of receipt is not significantly related to suicide rates and barely affects the coefficient on whether a given subdistrict received the program (table A.18). We find comparable effect sizes for short-run and medium-run effects of the program. This finding is inconsistent with a model of reference dependence over past income levels, which predicts declining effects on suicides as soon as people's reference point adjusts to the new income level.

\section{Robustness: Outcome Definitions}

One concern with our analysis could be that the definitions of the suicide rate change over time. We provide three pieces of evidence that demonstrate the robustness of our results to using less rich but time-invariant measures of subdistrict suicides.

First, we employ a measure of the suicide rate using the Poisson extrapolation described in section IIC. Using this extrapolated suicide rate as the outcome for all years, we see the same treatment effect patterns with similar effect sizes (columns 1 to 5 of table A. 4 and figures A.6 and A.7). Second, we use a version of the suicide rate based on the number of villages in a given subdistrict that report at least one suicide. This is effectively a truncated version of our main outcome variable. Our treatment effect estimates with this outcome definition remain largely unchanged (columns 6 to 10 of table A.4). Third, we employ a binary variable indicating whether any suicide occurred in a given subdistrict-year. The treatment effects are qualitatively similar to our main specification (columns 11 to 15 of table A.4). Our preferred specification implies that receiving the cash transfer reduces the likelihood of at least one suicide by 6 percentage points, or $12 \%$. Thus, it seems that changes in the survey structure over time do not affect our results.

Another concern could be that the cash transfer program affects migration patterns and thereby shapes our treatment effect estimates. To test whether these potential changes in migration affect our results, we estimate treatment effects on two further outcomes not subject to this bias. The first one is the suicide rate per 100,000 inhabitants using the 2005 population for all years. This definition of the suicide rate is unaffected by changes in migration induced by the cash transfer. We find that with this measure, treatment effects on the suicide rate are still highly significant (columns 1 to 5 of table A.5). The second alternative outcome variable is the number of suicides. ${ }^{24}$ Again, the treatment effect patterns remain largely unchanged. The point estimate of our preferred specification indicates that the cash transfer program decreased the number of suicides per subdistrict by 0.2 (column 11 of table

\footnotetext{
${ }^{24}$ For this analysis, we stick with the definition used for our main outcome variable and use the actual number of suicides when available. The results remain very similar when we use the number of villages with at least one suicide as the outcome (results available on request).
}

A.5). This set of results suggests that changes in migration do not drive our main results. ${ }^{25}$

\section{E. Agricultural Productivity Shocks and Suicides}

The evidence from previous sections shows that a positive economic shock, namely, the receipt of a conditional cash transfer, can lower suicide rates. In this section, we examine whether agricultural productivity shocks, as measured by rainfall, also affect suicide rates.

Advantages of rainfall analysis. The rainfall analysis has at least two advantages compared to the analysis of the cash transfer program: First, it enables us to examine whether positive and negative income shocks have symmetric effects on the incidence of suicide. Second, it allows us to retrieve estimates with no concerns regarding differential social desirability bias between the treatment and the control group. ${ }^{26}$

Data. Our empirical strategy relies on the following two facts. First, the agricultural sector in Indonesia is to a large extent governed by seasonal monsoon rainfall. Second, Indonesian rainfall exhibits substantial variability within a given year across subdistricts, as well as within subdistricts over time. To examine the causal effect of agricultural productivity shocks, we leverage the ERA-Interim Reanalysis data set, which provides precipitation data from 1979 to 2016 on a $0.25 \times 0.25$ degree resolution (roughly a $27.5 \times 27.5$ kilometer grid at the equator). We define rainfall at the subdistrict level as the weighted average rainfall at the five grid points closest to the geometric center of the subdistrict. ${ }^{27}$ Each grid point is weighted with the inverse of the squared distances to the subdistrict center. Reanalysis data are based on a mix of real weather observations (station and satellite data) and an atmospheric climate model. The main advantage of reanalysis data is the homogeneous data quality across time and space, which alleviates the concern of endogenous placement of weather stations. The rainfall data are matched to the 2000 subdistrict boundaries. We use suicide data from the 2000, 2003, 2005, 2011, and 2014 waves of the Indonesian village census. As before, our main outcome variable of interest, $y_{s t}$, is the suicide rate in a given subdistrict, $s$, at time $t$.

Specification and results. We follow Maccini and Yang (2009) and calculate rainfall in a particular year by focusing on rainfall in agricultural seasons (rather than in calendar years). As in Maccini and Yang (2009) we define rainfall,

\footnotetext{
${ }^{25}$ The results for the RCT are also robust to changing outcome definitions, though the results are more noisily measured (tables A.10 and A.11).

${ }^{26}$ One may be concerned that village heads whose villages are in receipt of the PKH program report more favorable outcomes, but this critique does not apply to the rainfall analysis.

${ }^{27}$ We lack coordinates for fourteen subdistricts. We use average rainfall and coordinates of other subdistricts in the same district for these subdistricts. For one district, all subdistricts have missing coordinates. For those, we use province-level average rainfall and coordinates.
} 
Table 4.--Interactions between Agricultural Productivity Shocks and The cash Transfers

\begin{tabular}{|c|c|c|c|c|c|c|}
\hline \multicolumn{7}{|c|}{ Dependent Variable: Suicide Rate } \\
\hline & (1) & (2) & (3) & (4) & (5) & (6) \\
\hline \multirow[t]{3}{*}{ Rain (z-scored) } & $-0.082^{*}$ & $-0.112^{* *}$ & $-0.081^{*}$ & $-0.106^{* *}$ & $-0.094^{*}$ & $-0.129^{* *}$ \\
\hline & $(0.045)$ & $(0.050)$ & $1(0.044)$ & $(0.048)$ & $(0.049)$ & $(0.054)$ \\
\hline & [0.039] & {$[0.043]$} & [0.038] & {$[0.042]$} & {$[0.039]$} & {$[0.046]$} \\
\hline \multirow[t]{3}{*}{ Treatment } & & $-0.216^{* *}$ & & $-0.255^{* *}$ & & -0.193 \\
\hline & & $(0.109)$ & & $(0.101)$ & & $(0.117)$ \\
\hline & & {$[0.122]$} & & {$[0.115]$} & & {$[0.130]$} \\
\hline \multirow[t]{3}{*}{ Rain $(z$-scored $) \times$ Treat } & & $0.118^{*}$ & & 0.096 & & $0.133^{*}$ \\
\hline & & $(0.072)$ & & $(0.068)$ & & $(0.079)$ \\
\hline & & {$[0.070]$} & & {$[0.068]$} & & {$[0.077]$} \\
\hline Subdistrict FE & Yes & Yes & Yes & Yes & Yes & Yes \\
\hline Time FE & Yes & Yes & Yes & Yes & Yes & Yes \\
\hline Subdistrict trends & No & No & Yes & Yes & No & No \\
\hline Include lagged rainfall & No & No & No & No & Yes & Yes \\
\hline Number & 15,690 & 15,690 & 15,690 & 15,690 & 15,690 & 15,690 \\
\hline Census waves & $00-14$ & $00-14$ & $00-14$ & $00-14$ & $00-14$ & $00-14$ \\
\hline
\end{tabular}

The table displays the impact of rainfall on the suicide rate. The suicide rate is defined as explained in table 2. Odd columns report the impact of standardized rainfall on suicides. Even columns include the treatment variable from the conditional cash transfer rollout and the interaction with rainfall. All specifications include subdistrict and year fixed effects. Columns 3 and 4 control for subdistrict time trends. Columns 5 and 6 include the first, second and third lag of rainfall. Parentheses report Conley (1999) standard errors, allowing for arbitrary time correlation and two-dimensional spatial correlation within a $100 \mathrm{~km}$ radius of the subdistrict centroid (used for stars). Standard errors clustered at the district level are in square brackets. ${ }^{*} p<0.10,{ }^{* *} p<0.05$, and ${ }^{* * *} p<0.01$.

$\operatorname{zrain}_{s t}$, as the normalized deviation of rainfall from the longterm mean within a given subdistrict. ${ }^{28}$ This measure of rainfall has been shown to significantly and strongly predict rice output (Levine \& Yang, 2014). In all of our specifications, we control for subdistrict-level fixed effects, $\alpha_{s}$, as well as time fixed effects, $\phi_{t}$. As rainfall is heavily spatially correlated, we report Conley (1999) standard errors allowing for arbitrary spatial and temporal correlation of error terms in a 100 kilometer, radius around the subdistrict center (we also report standard errors clustered at the district level). We estimate the following equation, using the 2005 population to weight the subdistrict observations to make the analysis comparable to the cash transfer estimates:

$$
y_{s t}=\gamma_{1} \operatorname{zrain}_{s t}+\alpha_{s}+\phi_{t}+\varepsilon_{s t} .
$$

Table 4 provides evidence that higher rainfall significantly reduces suicides. In column 1 , we show that increases in subdistrict rainfall by 1 standard deviation from the long-run subdistrict mean lowers the suicide rate by 0.08 . In column 3 , we include subdistrict trends to rule out the possibility that differential trends can explain our findings. Our results are virtually unchanged by the inclusion of trends and, if anything, become somewhat stronger. ${ }^{29}$ Column 5 assesses the sensitivity of our estimates by also controlling for the first, second, and third lag of rainfall. This leaves our estimated coefficients largely unaffected. Our estimated coefficients in-

\footnotetext{
${ }^{28}$ We use rainfall data from 1979 to 2016 to construct the subdistrictspecific leave-one-out long-run means and leave-one-out long-run standard deviations. As Indonesia is located around the equator, temperature is relatively constant and therefore does not have effects on agricultural yields (Kleemans \& Magruder, 2018).

${ }^{29}$ We also estimate the impact of a linearly detrended (at the subdistrict level) measure of rainfall on the suicide rate (tables A.22 and A.23). The results are slightly weaker but qualitatively in line with the results from the main specification.
}

crease further in both economic and statistical significance once we give equal weight to subdistricts, that is, once we do not weight by population size (see table A.19).

Table A.20 tests whether the relationship between positive and negative rainfall shocks and the suicide rate is approximately symmetric. To do so we augment the above equation by two dummy variables: posshock $\mathrm{k}_{s t}$, taking a value of 1 for subdistricts experiencing a positive shock in rainfall (top onethird of the standardized rainfall distribution in our sample) and negshock $\mathrm{k}_{s t}$, taking a value of 1 for districts experiencing a negative shock in rainfall $(0.33 \%$ of the standardized rainfall distribution in our sample). Then we estimate the following equation:

$$
\begin{aligned}
y_{s t}= & \beta_{1} \text { zrain }_{s t}+\beta_{2} \text { posshock }_{s t}+\beta_{3} \text { negshock }_{s t} \\
& +\alpha_{s}+\phi_{t}+\varepsilon_{s t} .
\end{aligned}
$$

We find little evidence of asymmetric responses to shocks. While the absolute value of the point estimates for $\beta_{2}$ is slightly larger than the estimates of $\beta_{3}$, we cannot reject that they are of equal size. In figure 3 , we nonparametrically assess the relationship between rainfall and suicide. To do so, we partial out time fixed effects, subdistrict fixed effects, and subdistrict trends from both suicide rates and the rainfall measure. Then we use the predicted residuals from these regressions to run local polynomial regressions between these residuals. Figure 3 highlights a strong, negative relationship between rainfall and the suicide rate, confirming our previous result that the responses to positive and negative rainfall shocks are fairly symmetric and that the overall relationship is approximately linear. However, at the top end of the rainfall distribution, we observe a slight flattening of the relationship consistent with a convex relationship between the suicide rate and income. 


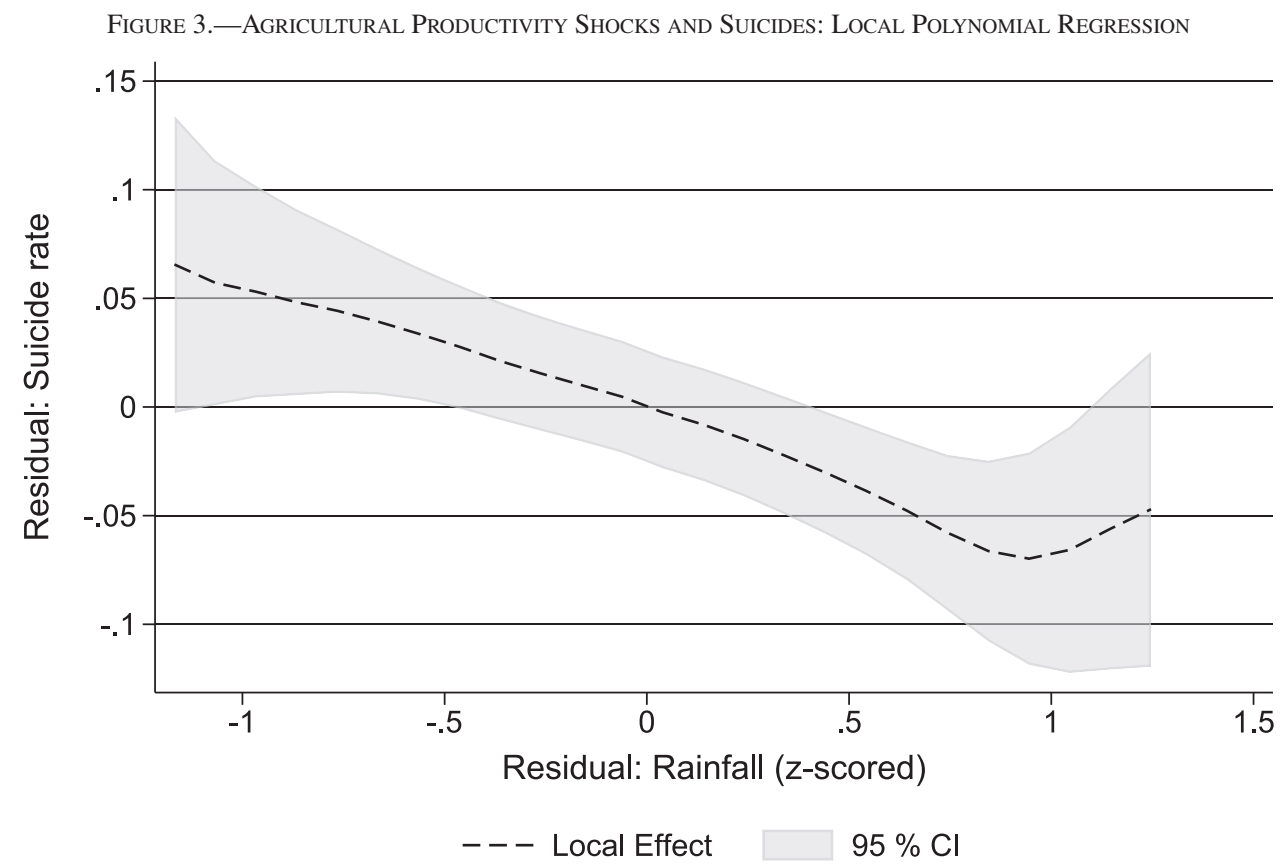

The figure displays a local polynomial regression of the residuals of the suicide rate and the residual of standardized rainfall using PODES 2000, 2003, 2005, 2011, and 2014. Residuals are obtained from a regression with time and subdistrict fixed effects and subdistrict time trends. We employ population weights from 2005 in our estimations. We employ an Epanechnikov kernel with a bandwidth of 0.44 . The top and bottom percentiles of the residual rainfall distribution are omitted because of concerns about biased estimates close to the limits (Li \& Racine, 2006). The suicide rate is defined as described in figure 1.

\section{F. Cash Transfers and Agricultural Productivity Shocks}

Do the cash transfers mitigate the adverse effects of agricultural productivity shocks on suicides? If economic hardship caused by negative economic shocks affects suicide rates, then we would expect cash transfers to more strongly reduce suicide rates in the face of negative economic shocks. We test whether there are significant interactions between receiving the cash transfer, Treat ${ }_{s t}$, and rainfall, zrain $_{s t}$. We leverage the suicide data from 2000 to 2014 and estimate the following equation, reporting Conley standard errors and standard errors clustered at the district level (as in all other main specifications, we use population size from 2005 to weight the observations):

$$
\begin{aligned}
y_{s t}= & \gamma_{1} \text { zrain }_{s t}+\gamma_{2} \text { Treat }_{s t}+\gamma_{3} \text { Zrain }_{s t} \times \text { Treat }_{s t} \\
& +\alpha_{s}+\phi_{t}+\varepsilon_{s t} .
\end{aligned}
$$

Our key coefficient of interest is $\gamma_{3}$. Column 2 of table 4 reveals a significant interaction effect, consistent with the idea that cash transfers are more (less) effective at lowering suicides in years with lower (higher) agricultural productivity. Our estimates imply that cash transfers lower suicides by 0.3 suicides per 100,000 inhabitants in a year with subdistrict rainfall 1 standard deviation below its long-run mean, but only lower suicides by 0.1 suicides per 100,000 inhabitants in a year with subdistrict rainfall 1 standard deviation above its long-run mean.

These effects become slightly smaller and statistically insignificant but remain economically meaningful once we control for subdistrict trends. This most likely reflects the lim- ited power for studying interaction effects after controlling for subdistrict trends. The estimated effects of the interaction between the cash transfer and rainfall are much stronger in specifications that do not use population weighting (see table A.19). This stems from the fact that rainfall more strongly affects incomes in more rural subdistricts with lower population size. We also analyze the effect of the cash transfer separately for positive and negative rainfall shocks in table A.21. While this analysis is limited by lower statistical power, the estimates suggest that the cash transfer program reduces the effects of both positive and negative agricultural productivity shocks symmetrically.

The observed heterogeneity in treatment effects suggests that social welfare programs can dampen the effects of negative and positive economic shocks. Put differently, the cash transfer program breaks the relationship between agricultural productivity shocks and suicides. ${ }^{30}$ The finding of a positive interaction effect between rainfall and the receipt of the cash transfer suggests that the relationship between the suicide rate and income is convex, not linear or concave.

Further heterogeneity. Do other covariates predict heterogeneous responses to the cash transfer program? There is no statistically significant heterogeneity by any predetermined characteristics (fraction of farmers, fraction poor, per capita expenditure, per capita crimes, per capita social institutions, and per capita health institutions; see table A.27). However, our effective statistical power to detect statistical differences

\footnotetext{
${ }^{30}$ The interaction result also suggests that the effects of the cash transfer are not driven by differential social desirability bias between the treatment and the control group.
} 
INCOME SHOCKS AND SUICIDES

TABLe 5.--IMPACT OF RAINFALl on CONSUMPTION AND DEPRESSION z-SCORES

\begin{tabular}{|c|c|c|c|c|c|c|}
\hline & \multicolumn{3}{|c|}{ Working in Agriculture } & \multicolumn{3}{|c|}{ Not Working in Agriculture } \\
\hline & $\begin{array}{c}\text { (1) } \\
\text { Consumption }\end{array}$ & $\begin{array}{c}\text { (2) } \\
\text { Log consumption }\end{array}$ & $\begin{array}{c}(3) \\
\text { Depression }(\mathrm{z})\end{array}$ & $\begin{array}{c}\text { (4) } \\
\text { Consumption }\end{array}$ & $\begin{array}{c}\text { (5) } \\
\text { Log consumption }\end{array}$ & $\begin{array}{c}(6) \\
\text { Depression (z) }\end{array}$ \\
\hline Rain (z-score) & $\begin{array}{c}39706.205^{\text {**** }} \\
(14587.567) \\
{[9805.642]}\end{array}$ & $\begin{array}{l}0.069^{* * *} \\
(0.022) \\
{[0.019]}\end{array}$ & $\begin{array}{c}-0.124^{* * *} \\
(0.042) \\
{[0.042]}\end{array}$ & $\begin{array}{c}11687.256 \\
(15481.365) \\
{[14631.741]}\end{array}$ & $\begin{array}{c}0.008 \\
(0.018) \\
{[0.017]}\end{array}$ & $\begin{array}{c}-0.008 \\
(0.050) \\
{[0.053]}\end{array}$ \\
\hline $\begin{array}{l}\text { Number } \\
\text { IFLS waves used }\end{array}$ & $\begin{array}{c}12,790 \\
1-5\end{array}$ & $\begin{array}{c}12,790 \\
1-5\end{array}$ & $\begin{array}{c}5,192 \\
4-5\end{array}$ & $\begin{array}{c}8,356 \\
1-5\end{array}$ & $\begin{array}{c}8,356 \\
1-5\end{array}$ & $\begin{array}{c}3,420 \\
4-5\end{array}$ \\
\hline
\end{tabular}

The table displays the impact of rainfall on monthly per capita household consumption and depression $z$-scores in the Indonesian Family Life Survey (IFLS). The sample is restricted to individuals tracked in all five waves of the IFLS. Columns 1 to 3 use a sample of individuals living in households with at least one member working in agriculture (self-employed without or with temporary workers, or as casual or family workers) in any of the five waves. Columns 4 to 6 use individuals from households without any agricultural worker. Consumption is measured in 2005 Indonesian rupiah. Depression scores are measured using the 10-item CES-D scale (Radloff, 1997). All columns include individual and time fixed effects. Parentheses report Conley (1999) standard errors, allowing for arbitrary time correlation and spatial correlation within a 100 kilometer radius of the subdistrict centroid (used for asterisks). Standard errors clustered at the district level are in brackets. ${ }^{*} p<0.10,{ }^{* *} p<0.05$, and ${ }^{* * *} p<0.01$.

in treatment effects across groups is quite limited (see the minimum detectable effect sizes in table A.27).

\section{Mechanism}

We next provide suggestive evidence in favor of depression as a channel through which economic circumstances could affect people's inclination to commit suicide. In particular, we show that economic shocks directly affect a measure of depression in line with the framework in section IIA. Finally, we examine the importance of several potential subdistrictlevel mediators.

\section{A. Economic Shocks and Depression: Microevidence}

To provide evidence that economic circumstances may affect people's inclination to commit suicide through changes in mental health, we use unique individual-level data on depression from the Indonesian Family Life Survey (IFLS). The IFLS waves 4 and 5 (in 2007 and 2014) administer a 10-question version of the CES-D depression scale (Radloff, 1997). Moreover, we use rich data on household expenditure available for all five waves of the IFLS (the sample is restricted to individuals observed in all five IFLS waves).

As in section IIIE, we exploit agricultural productivity shocks to study the effects of economic circumstances. We assess the effects of rainfall, $\operatorname{zrain}_{s t}$, on depression, depression $_{\text {ist }}$, as measured by the CES-D score and monthly per capita household expenditure, $\exp _{i s t}$, in levels and logs. Our objects of interest are households with at least one agricultural worker, the group of households whose income is most strongly dependent on rainfall. ${ }^{31}$ We employ the same subdistrict-level rainfall measure as in section IIIE, and report both Conley standard errors and standard errors clustered at the district level. We also include individual-level fixed effects, $\alpha_{i}$, in our regression which allows us to control for time-

\footnotetext{
${ }^{31}$ Households count as "working in agriculture" if any household member works in agriculture in self-employment (without permanent employees) or as a casual or family worker in any of the five IFLS waves. There is no sector information for IFLS Wave 1. We therefore use working "in self-employment without permanent employees" or working as "temporary worker" as proxies.
}

invariant, individual-specific unobservables. Specifically, we estimate the following equation:

$$
\mathrm{y}_{i s t}=\delta_{1} \operatorname{zrain}_{s t}+\alpha_{i}+\phi_{t}+\varepsilon_{i s t} .
$$

Table 5 shows that a 1 standard deviation increase in rainfall increases monthly per capita consumption of farmers by 40,000 rupiah (column 1), monthly log consumption by $6.9 \%$ (column 2), ${ }^{32}$ and decreases depression by 0.12 standard deviations (column 3). ${ }^{33}$ Columns 4 to 6 of table 5 also provide evidence that the rainfall shocks operate through an economic mechanism by showing that both depression and consumption of nonfarmers do not respond to rainfall shocks. This suggests that our estimated effects on depression do not operate through direct effects of weather on mental health. Indeed, the coefficients on the effects of rainfall on log consumption and mental health are statistically different between farmers and nonfarmers ( $p=0.006$ and $p=0.06$, respectively). ${ }^{34}$ We also use the individual-level data to study heterogeneous effects of agricultural productivity shocks on depression. We find that depression scores of individuals with higher baseline expenditure are more strongly affected by rainfall shocks (table A.24). This suggests a convex relationship between depression and income and is consistent with the finding that cash transfers more strongly reduce suicides in the presence of negative agricultural productivity shocks. The effects are also significantly larger for women and below-median-age individuals.

Mediation analysis. What other factors could account for the effects of the cash transfer program on suicide rates? The cash transfer increased recipients' welfare by increasing their consumption and improving their health outcomes (World Bank, 2011). Guided by this, we examine several potential subdistrict-level mediators, including local crime rates, health and education institutions, and social organizations, through which the cash transfer program could lower

\footnotetext{
${ }^{32} \mathrm{~A} 6.9 \%$ increase over the median per capita consumption across all years corresponds to about 18,000 rupiahs or roughly $\$ 1.80$ at 2005 prices.

${ }^{33} \mathrm{We}$ also find that individuals who received the PKH cash transfer by 2014 had higher depression scores in 2007 (0.14 standard deviation; see table A.25).

${ }^{34}$ The difference in effects on consumption levels are marginally insignificant $(p=0.162)$.
} 
the incidence of suicides. We therefore include time-varying endogenous controls at the subdistrict level in our main specification of interest. These controls could have been affected by the cash transfer in systematic ways and therefore act as a channel through which our treatment effects operate. However, we find little evidence that any subdistrict-level institutions mediate our results. The treatment effect estimates hardly move when the potential mediators are included (table A.26). This mediation analysis is limited by the fact that we have to rely on subdistrict-level mediators and points to the importance of individual-level mediators.

\section{Interpreting Effect Sizes}

The impact of cash transfers on suicides of cash transfer recipients is quantitatively very large if we assume no spillovers in suicides. Spillovers similar to those identified in previous work are consistent with moderately large direct effects. Implied direct per-dollar effects of income on suicides identified using rainfall are significantly smaller than those from cash transfers.

\section{A. Cash Transfer Program}

There are two main factors to consider when calculating the size of the cash transfer program on recipients. First, there is a strong economic gradient in the suicide rate. The correlation between the fraction of individuals classified as poor and the suicide rate is large and positive (see section A.2). A $10 \%$ higher share of the poor population is, on average, associated with a 0.14 higher suicide rate in 2005 (table A.1). A back-of-the-envelope calculation suggests that poor individuals are 2.24 times more likely to commit suicide than nonpoor households. ${ }^{35}$ Second, there are likely two types of spillover effects on nontreated individuals. The first is that suicides are highly contagious (Hedström et al., 2008). Moreover, the conditional cash transfer might have positive economic spillovers to households not receiving the PKH program (Angelucci \& De Giorgi, 2009). Thus, we would expect that reducing suicides among PKH recipients may also decrease suicides among nonrecipients. Assuming no spillovers, our preferred treatment effect estimate ( 0.36 suicides per 100,000 people) implies that the suicide rate among the poor decreased by $89 \%$ of the implied mean suicide rate, or 3.6 suicides per 100,000 . This effect size would imply that the suicide rate among PKH recipients who received the transfer is lower than the rate among nonrecipients after treatment. Therefore, it may be more reasonable to calculate the implied suicide rate reduction among PKH recipients assuming that the cash transfer equalized suicide rates between poor and nonpoor households. This yields an estimate of a direct treatment effect of $58.7 \%$ of the implied control group mean for PKH recipients, or 2.36 per 100,000 , and an indirect effect of 0.12

\footnotetext{
${ }^{35}$ For details for this and the following back-of-the-envelope calculations, see section A.1.
}

for nonpoor individuals (4.9\% of the direct treatment effect). Our estimated effect size of spillovers is modest compared to estimates from the literature on suicide contagion (Hedström et al., 2008). We estimate that the program prevented about 1,065 suicides—one suicide for every $\$ 672,000$ spent.

\section{B. Agricultural Productivity Shocks}

To estimate the per dollar effect size of agricultural productivity shocks, we use microdata from the Indonesian Family Life Survey. We show that a 1 standard deviation change in rainfall induces a $6.9 \%$ change in monthly per capita consumption for individuals in agricultural households (table 5). This translates into a change of about $\$ 1.80$ of monthly per capita consumption at the median consumption level. This is equivalent to a yearly change in per capita expenditure of \$21.60 at 2005 prices per 1 standard deviation change, a similar magnitude as the annual cash transfer amount. We use this measure as our preferred dollar value to deal with outliers in the consumption data, which might strongly influence the level estimates. Assuming no spillovers to nonfarmers, our estimates suggest that an increase in annual per capita expenditure of $\$ 21.60$ decreases the suicide rate by $7.4 \%$ of the implied mean suicide rate for farmers across all periods, or 0.14 per 100,000 farmers.

\section{Effect Size Comparison}

Next, we compare the per dollar impact of the cash transfer program and the agricultural productivity shocks. This comparison requires strong assumptions, such as the baseline suicide rates of different groups of people. The implied effect sizes in terms of percentage changes in the suicide rate for a $\$ 10.00$ change in income or consumption (assuming no spillovers) for the cash transfer program are roughly 12 times larger than of those of rainfall shocks (25 times larger in absolute terms of the suicide rate). Extrapolating linearly, we find that an increase in the annual per capita income or consumption by $\$ 10.00$ decreased the suicide rate of poor individuals and farmers by $39.64 \%$ (1.61 suicides) or $3.34 \%$ (0.06 suicides), respectively. We can reject the hypothesis of equality of the implied direct effect of the cash transfer and the rainfall shocks in dollar terms $(p<0.01)$. This finding implies that the income shock targeted at initially poorer individuals was more effective and is therefore consistent with a convex relationship between the suicide rate and income.

The larger per dollar impact of the cash transfer program compared to agricultural productivity shocks of the same value is in line with the predictions outlined in section IIA. There are several reasons why the cash transfer could have larger effects. First, the six-year duration of the program substantially decreases uncertainty about future income streams. Second, it is possible that program recipients expected that the cash transfer might continue after the initial six-year period, which would substantially increase the expected net present 
value of the program. Third, the conditionalities of the cash transfer may have an additional effect on mental health as they may induce more social interactions and may relieve stress related to the children. Fourth, individuals classified as poor have higher implied mean suicide rates than farmers. Thus, the cash transfer program targeted a high-risk population and therefore likely had a larger impact. Fifth, we assume that all farmers are affected equally by rainfall, but there is a large degree of heterogeneity in how rainfall affects harvest depending, for example, on the type of crop. Sixth, it is possible that the cash transfers have a direct psychological effect. They may also act as a signal that the government may be willing to offer insurance from bad outcomes more generally, thereby shifting recipients' economic outlook.

\section{Conclusion}

We establish an important economic dimension in suicides. Using the nationwide rollout of a conditional cash transfer program and a randomized experiment of the same program, we show that the program decreased suicides by approximately 0.36 per 100,000 inhabitants. We also show that agricultural productivity shocks, proxied by rainfall, significantly affect suicide rates. A 1 standard deviation increase in rainfall lowers the number of suicides per 100,000 inhabitants by approximately 0.08 . Moreover, we establish that cash transfers lower suicides most effectively in subdistricts experiencing negative agricultural productivity shocks. This supports the idea that social welfare programs can mitigate the adverse effects of negative economic shocks on mental health. Our evidence points to an important role of government policies in alleviating the consequences of poverty on mental health.

Using microdata from the Indonesian Family Life Panel, we show that economic shocks may affect people's inclination to commit suicide through mental health. However, understanding the exact mechanisms through which economic shocks ignite suicidal behavior leaves ample scope for future research. We believe that there are several fruitful avenues for future research. First, we need better microdata on how economic circumstances affect mental health-for example, through elevated stress levels or the formation of economic beliefs and preferences. Second, more research should be carried out to understand which combination of economic and psychological interventions is best suited to increase mental health and prevent suicides. Third, we need a better understanding of which populations should be targeted to increase mental health and lower suicide rates most cost-effectively.

\section{REFERENCES}

Adhvaryu, Achyuta, James Fenske, and Anant Nyshadham, "Early Life Circumstance and Adult Mental Health," Journal of Political Economy 127 (2019), 1516-1549.

Allcott, Hunt, "Site Selection Bias in Program Evaluation," Quarterly Journal of Economics 130 (2015), 1117-1165.

Angelucci, Manuela, and Giacomo De Giorgi, "Indirect Effects of an Aid Program: How Do Cash Transfers Affect Ineligibles' Consumption?" American Economic Review 99 (2009), 486-508.
Appleby, Louis, Jayne Cooper, Tim Amos, and Brian Faragher, "Psychological Autopsy Study of Suicides by People Aged under 35," British Journal of Psychiatry 175 (1999), 168-174.

Baicker, Katherine, Sarah L. Taubman, Heidi L. Allen, Mira Bernstein, Jonathan H. Gruber, Joseph P. Newhouse, Eric C. Schneider, Bill J. Wright, Alan M. Zaslavsky, and Amy N. Finkelstein, "The Oregon Experiment-Effects of Medicaid on Clinical Outcomes," New England Journal of Medicine 368 (2013), 1713-1722.

Baird, Sarah, Jacobus De Hoop, and Berk Özler, "Income Shocks and Adolescent Mental Health," Journal of Human Resources 48 (2013), 370-403.

Baird, Sarah, Craig McIntosh, and Berk Özler, "Cash or Condition? Evidence from a Cash Transfer Experiment," Quarterly Journal of Economics, 126 (2011), 1709-1753.

Banerjee, Abhijit V., Rema Hanna, Gabriel E. Kreindler, and Benjamin A. Olken, "Debunking the Stereotype of the Lazy Welfare Recipient: Evidence from Cash Transfer Programs," World Bank Research Observer 32 (2017), 155-184.

Bazzi, Sam, and Matthew Gudgeon, "The Political Boundaries of Ethnic Divisions," NBER working paper 24625 (2018).

Becker, Sascha O., and Ludger Woessmann, "Social Cohesion, Religious Beliefs, and the Effect of Protestantism on Suicide," this REVIEW 100 (2018), 377-391.

Blüml, Victor, Nestor D. Kapusta, Stephan Döring, Elmar Brähler, Birgit Wagner, and Anette Kersting, "Personality Factors and Suicide Risk in a Representative Sample of the German General Population," PLoS One 8 (2013), e76646.

Boldrini, Maura, and J. John Mann, "Depression and Suicide" (pp. 709729), in Michael J.Zigmond, Lewis P. Rowland, and Joseph T. Coyle, eds., Neurobiology of Brain Disorders (London: Academic Press, 2015).

Cahyadi, Nur, Rema Hanna, Benjamin A. Olken, Rizal Adi Prima, Elan Satriawan, and Ekki Syamsulhakim, "Cumulative Impacts of Conditional Cash Transfer Programs: Experimental Evidence from Indonesia," NBER working paper 24670 (2018).

Campaniello, Nadia, Theodoros M. Diasakos, and Giovanni Mastrobuoni, "Rationalizable Suicides: Evidence from Changes in Inmates" Expected Length of Sentence," Journal of the European Economic Association 15 (2017), 388-428.

Carleton, Tamma, "Crop-Damaging Temperatures Increase Suicide Rates in India," Proceedings of the National Academy of Sciences 114 (2017), 8746-8751.

Cavanagh, Jonathan T., Alan J. Carson, Michael Sharpe, and Stephen M. Lawrie, "Psychological Autopsy Studies of Suicide: A Systematic Review," Psychological Medicine 33 (2003), 395-405.

Cesarini, David, Erik Lindqvist, Robert Östling, and Björn Wallace, "Wealth, Health, and Child Development: Evidence from Administrative Data on Swedish Lottery Players," Quarterly Journal of Economics 131 (2015), 687-738

Chang, Shu-Sen, David Stuckler, Paul Yip, and David Gunnell, "Impact of 2008 Global Economic Crisis on Suicide: Time Trend Study in 54 Countries," British Medical Journal, 347 (2013), f5239.

Conley, Timothy G., "GMM Estimation with Cross Sectional Dependence," Journal of Econometrics 92 (1999), 1-45.

Cutler, David M., Edward L. Glaeser, and Karen E. Norberg, "Explaining the Rise in Youth Suicide" (pp. 219-270), in Jonathan Gruber, ed., Risky Behavior among Youths: An Economic Analysis (Chicago: University of Chicago Press, 2001).

Daly, Mary C, Daniel J. Wilson, and Norman J. Johnson, "Relative Status and Well-Being: Evidence from US Suicide Deaths," this REVIEW 95 (2013), 1480-1500.

Das, Jishnu, Quy-Toan Do, Jed Friedman, David McKenzie, and Kinnon Scott, "Mental Health and Poverty in Developing Countries: Revisiting the Relationship," Social Science and Medicine 65 (2007), 467-480

Deaton, Angus, "Instruments, Randomization, and Learning about Development," Journal of Economic Literature 48 (2010), 424 455.

Devoto, Florencia, Esther Duflo, Pascaline Dupas, William Parienté, and Vincent Pons, "Happiness on Tap: Piped Water Adoption in Urban Morocco," American Economic Journal: Economic Policy 4 (2012), 68-99.

Frederick, Shane, and George Loewenstein, "Hedonic Adaptation" (pp. 302-329), in Daniel Kahneman, Ed Diener, and Norbert 
Schwartz, eds., The Foundations of Hedonic Psychology (New York: Russell Sage Foundation, 1999).

Friedman, Jed, and Duncan Thomas, "Psychological Health before, during, and after an Economic Crisis: Results from Indonesia, 1993-2000," World Bank Economic Review 23 (2009), 57-76.

Galiani, Sebastian, Paul J. Gertler, and Raimundo Undurraga, "The HalfLife of Happiness: Hedonic Adaptation in the Subjective Well-Being of Poor Slum Dwellers to a Large Improvement in Housing," Journal of the European Economic Association 16 (2018), 1189-1233.

Gardner, Jonathan, and Andrew J. Oswald, "Money and Mental Well-Being: A Longitudinal Study of Medium-Sized Lottery Wins," Journal of Health Economics 26 (2007), 49-60.

Haushofer, Johannes, and Ernst Fehr, "On the Psychology of Poverty," Science 344 (2014), 862-867.

Haushofer, Johannes, and Jeremy Shapiro, "The Short-Term Impact of Unconditional Cash Transfers to the Poor: Experimental Evidence from Kenya," Quarterly Journal of Economics 131 (2016), 1973-2042.

Hawton, Keith, Carolina Casañas i Comabella, Camilla Haw, and Kate Saunders, "Risk Factors for Suicide in Individuals with Depression: A Systematic Review," Journal of Affective Disorders 147 (2013), $17-28$

Hedström, Peter, Ka-Yuet Liu, and Monica K. Nordvik, "Interaction Domains and Suicide: A Population-Based Panel Study of Suicides in Stockholm, 1991-1999," Social Forces 87 (2008), 713-740.

Joiner, Thomas, Why People Die by Suicide (Cambridge, MA: Harvard University Press, 2005).

Kleemans, Marieke, and Jeremy Magruder, "Labor Market Changes in Response to Immigration: Evidence from Internal Migration Driven by Weather Stocks," Economic Journal 128 (2018), 2032-2065.

Kling, Jeffrey R., Jeffrey B. Liebman, and Lawrence F. Katz, "Experimental Analysis of Neighborhood Effects," Econometrica 75 (2007), 83119.

Kuhn, Peter, Peter Kooreman, Adriaan Soetevent, and Arie Kapteyn, "The Effects of Lottery Prizes on Winners and Their Neighbors: Evidence from the Dutch Postcode Lottery," American Economic Review 101 (2011), 2226-2247.

Levine, David I., and Dean Yang, "The Impact of Rainfall on Rice Output in Indonesia," NBER working paper 20302 (2014).

Li, Qi, and Jeffrey Scott Racine, Nonparametric Econometrics Theory and Practice (Princeton: Princeton University Press, 2006).

Ludwig, Jens, Dave E. Marcotte, and Karen Norberg, "Anti-Depressants and Suicide," Journal of Health Economics 28 (2009), 659-676.
Maccini, Sharon, and Dean Yang, "Under the Weather: Health, Schooling, and Economic Consequences of Early-Life Rainfall," American Economic Review 99 (2009), 1006-1026.

Mann, J. John, Christine Waternaux, Gretchen L. Haas, and Kevin M. Malone, "Toward a Clinical Model of Suicidal Behavior in Psychiatric Patients," American Journal of Psychiatry 156 (1999), 181189.

McInerney, Melissa, Jennifer M. Mellor, and Lauren Hersch Nicholas, "Recession Depression: Mental Health Effects of the 2008 Stock Market Crash," Journal of Health Economics 32 (2013), 10901104.

O'Connor, Rory C., and Matthew K. Nock, "The Psychology of Suicidal Behaviour," Lancet Psychiatry 1 (2014), 73-85.

Paxson, Christina, and Norbert Schady, "Cognitive Development among Young Children in Ecuador: The Roles of Wealth, Health, and Parenting," Journal of Human Resources 42 (2007), 49-84.

Persson, Petra, and Maya Rossin-Slater, "Family Ruptures, Stress, and the Mental Health of the Next Generation," American Economic Review 108 (2018), 1214-1252.

Radloff, Lenore Sawyer, "The CES-D Scale: A Self-Report Depression Scale for Research in the General Population," Applied Psychological Measurement 1 (1997), 385-401.

Reeves, Aaron, David Stuckler, Martin McKee, David Gunnell, Shu-Sen Chang, and Sanjay Basu, "Increase in State Suicide Rates in the USA During Economic Recession," Lancet 380 (2012), 1813-1814.

Roy, Alex, "Are There Genetic Factors in Suicide?" International Review of Psychiatry 4 (1992), 169-175.

Schilbach, Frank, Heather Schofield, and Sendhil Mullainathan, "The Psychological Lives of the Poor," American Economic Review: Papers and Proceedings 106 (2016), 435-440.

Stevenson, Betsey, and Justin Wolfers, "Bargaining in the Shadow of the Law: Divorce Laws and Family Distress," Quarterly Journal of Economics 12 (2006), 267-288.

WHO, Preventing Suicide: A Global Imperative (Geneva: World Health Organization, 2014).

World Bank, Program Keluarga Harapan: Main Findings from the Impact Evaluation of Indonesia's Pilot Household Conditional Cash Transfer Program (Washington, DC: World Bank, 2011). - Protecting Poor and Vulnerable Households in Indonesia (Washington, DC: World Bank, 2012).

Towards a Comprehensive, Integrated, and Effective Social Assistance System in Indonesia (Washington, DC: World Bank, 2017). 